\title{
Periodontal disease and systemic complications*
}

\section{Rui Vicente Oppermann ${ }^{(a)}$ Patricia Weidlich(a) Marta Liliana Musskopf ${ }^{(b)}$}

(a) Department of Periodontology, School of Dentistry, Univ Federal do Rio Grande do Sul - UFRGS, Porto Alegre, RS, Brazil.

(b) Graduate Program in Dentistry, School of Dentistry, Univ Federal do Rio Grande do Sul - UFRGS, Porto Alegre, RS, Brazil.
* Paper presented at the "Promotion of Oral Health in the Public and Private Context" National Symposium, held at the $15^{\text {th }}$ Congress of the Brazilian Association for Oral Health Promotion (ABOPREV), May 27-29, 2010, Brasília, DF, Brazil.

Declaration of Interests: The authors certify that they have no commercial or associative interest that represents a conflict of interest in connection with the manuscript.

Corresponding Author:

Rui Vicente Oppermann

E-mail: ruioppermann@gmail.com

Submitted: Nov 30, 2011

Accepted for publication: Jan 24, 2012

Last revision: Aug 20, 2012
Abstract: Periodontal diseases comprise a number of infectious and inflammatory conditions brought about by the interaction between supragingival and subgingival biofilms and the host inflammatory response. Periodontal diseases should be considered systemic conditions. This means that they are both modulated by the body's systems and play a role as a risk factor for systemic derangements. The current evidence supports some of these interactions, such as smoking as a risk factor for periodontal disease and diabetes mellitus, as both influenced by and influencing inflammatory changes in the periodontal tissue. Other potential associations are still being researched, such as obesity, hormonal changes, cardiovascular disease, and adverse outcomes in pregnancy. These, and others, still require further investigation before the repercussions of periodontal disease can be fully elucidated. Nevertheless, at the present time, the treatment of periodontal diseases-and, most importantly, their prevention-enables adequate intervention as a means of ensuring periodontal health.

Descriptors: Periodontal Diseases; Risk Factors; Smoking; Diabetes Mellitus; Cardiovascular Diseases.

\section{Introduction}

Periodontal diseases comprise a number of infectious and inflammatory conditions brought about by the interaction between supragingival and subgingival biofilms and the host inflammatory response. The very presence of biofilms, of the microorganisms that compose them, and of bacterial metabolites produced following colonization of the subgingival area elicits an inflammatory response. Activation of the host immune system, primarily for protective purposes, ultimately results in tissue destruction by triggering the synthesis and release of cytokines, proinflammatory mediators, and matrix metalloproteinases. The progression and severity of the periodontal destruction caused by periodontitis depends on the balance between the virulence of the local biofilm and the host immune response. ${ }^{1}$

\section{Historically recognized interactions}

A variety of systemic factors and conditions may interfere with and modulate the relationship between the microbial challenge and the host response. Smoking and diabetes have classically been recognized as risk factors for periodontitis; smokers and diabetics are at higher odds of de- 
veloping periodontitis as compared with individuals unaffected by either condition. ${ }^{2-6}$ Furthermore, longitudinal studies have shown that smokers are at a significantly higher risk of periodontal attachment loss than are never-smokers. ${ }^{7-9}$ In a longitudinal study of 101 patients with a 10-year follow-up, Bergström et al. ${ }^{7}$ found that the progression of attachment loss was significantly higher by increased exposure to smoking, after adjusting for age. In a cross-sectional study conducted on a representative sample from the Brazilian city of Porto Alegre and its metro area, moderate and heavy smokers were found to have a higher prevalence and extent of attachment loss than mild smokers and non-smokers alike. ${ }^{10}$ An association was found between smoking and attachment loss, with subjects classified as "heavy smokers" exhibiting an eightfold risk of attachment loss as compared with never-smokers (RR 8.2; 95\% CI 5.5-12.2). Calculation of the risk of attachment loss attributable to smoking revealed that subjects with a loss of $\geq 5 \mathrm{~mm}$ in at least $30 \%$ of teeth had a $71 \%$ risk of periodontitis attributable to smoking. ${ }^{11}$ These data suggest that a smoking cessation program would lead to an approximate $12 \%$ decrease in periodontitis, which would correspond to 90,000 potential cases in the study population.

The presence of diabetes has also been consistently reported as a risk factor for periodontitis in the literature. ${ }^{12,13}$ In the absence of adequate glycemic control, diabetes changes the host response to the microbial challenge, leading to a greater prevalence and extent of periodontal disease. U.S. studies carried out in a population of Native Americans with a high prevalence of type 2 diabetes have shown that diabetics are at a threefold risk of bone loss as compared with healthy subjects (OR 3.43; $95 \%$ CI 2.28-5.16)..$^{14,15}$ In the National Health and Nutrition Examination Survey conducted from 1988 to 1994 (NHANES III), diabetics over the age of 30 exhibited greater attachment loss, probing depth, and gingival recession and bleeding than non-diabetics, even after adjusting for age, gender, and ethnicity. ${ }^{16}$ Likewise, the percentage of affected teeth (as measured by assessment of four periodontal parameters) was approximately twice as high in diabetics as in non-diabetics. In Brazil, the
Porto Alegre study found significant differences in the prevalence of attachment loss between diabetics (self-reported) and non-diabetics, with a higher prevalence of $\geq 3 \mathrm{~mm}$ and $\geq 5 \mathrm{~mm}$ loss in the former group. ${ }^{10}$

In addition to diabetes and smoking, psychosocial factors and socioeconomic status have also been associated with periodontitis. The presence of factors such as stress, depression and anxiety often leads to poorer periodontal health. Stressed, anxious, or depressed persons tend to neglect their oral hygiene and often smoke more than usual and eat inadequately. These factors have a negative impact on the immune system. ${ }^{17}$ A case-control study was carried out to compare the prevalence of stress, anxiety, and depression in healthy controls and patients with periodontitis, using questionnaires validated for the Brazilian population. Associations were found between periodontitis and gender, smoking status, and educational attainment, whereas no significant association was found with any of the psychosocial factors assessed. ${ }^{18}$ Living in lower socioeconomic strata is also associated with increased rates of periodontal inflammation and attachment loss. ${ }^{19}$ In the Porto Alegre study, adults of lower socioeconomic status had a greater prevalence and extent of attachment loss, as compared with subjects of higher socioeconomic class. ${ }^{10}$ The same study also found that young adults living in underprivileged conditions had four times the odds of acquiring aggressive periodontitis than did those of higher socioeconomic status. ${ }^{20}$

\section{New associations worthy of consideration}

New interactions between periodontal disease and other systemic disorders have been the object of research in recent years. One such interaction is the possible modification of periodontal disease patterns in patients with Sjögren's syndrome. Sjögren's syndrome is a systemic autoimmune disease that characteristically affects the salivary glands (among other organs), producing xerostomia. The fact that patients with Sjögren's syndrome have a systemic immune disorder supports the hypothesis of a modi- 
fied response to the microbial challenge of periodontal disease. A case-control study comparing the clinical periodontal status of patients with Sjögren's syndrome to that of controls revealed a generally poorer periodontal condition in the former. ${ }^{21} \mathrm{~Pa}$ tients with secondary Sjögren's syndrome, who have other immune alterations in addition to glandular dysfunction, had particularly greater probing depths, attachment loss, and bleeding on probing, as compared with controls. The authors conclude that Sjögren's syndrome has an adverse effect on periodontal health, insofar as gingival inflammation was more evident in patients with the syndrome, particularly those with secondary Sjögren's.

Another systemic condition that alters host immune response is obesity, which has become a worldwide epidemic. Obesity is known to induce a hyperinflammatory state, with T-lymphocyte and monocyte/macrophage changes that could affect response to the microbial challenge. A study of over 700 subjects in Southern Brazil found an association between body mass index and periodontitis in women. ${ }^{22}$ Obese women had a relative risk of 2.1 for periodontitis as compared with non-obese women, and, upon multivariate analysis, non-smokers had a 3.4-fold risk of periodontitis as compared to women with a normal body mass index.

The ability of hormones to influence periodontal health is well established. The hormonal changes of puberty, as well as the increased hormone levels of pregnancy, can alter the periodontal inflammatory response to a similar biofilm load. The potential effect of menopause, which is characterized by an estrogen deficiency that influences bone metabolism, is a more recent concern. The association between menopause, hormonal replacement therapy, and periodontal attachment loss was investigated by Haas et al. The authors assessed 328 women and found a significantly greater rate of periodontitis in women who were not receiving hormonal replacement therapy as compared with premenopausal women $(64.4 \%$ versus $46.3 \%$ respectively, $\mathrm{p}=0.005)$. There was no significant difference in periodontitis rate between women receiving hormone replacement therapy and premenopausal women $\left(48.8 \%\right.$ and $46.3 \%$ respectively). ${ }^{23}$

\section{The effect of periodontal diseases on other systemic conditions}

In 1900, Hunter formally introduced the concept of focal disease. ${ }^{24}$ Ever since then, the interest in the role of oral infection in diseases and disorders of remote tissues and structures has varied widely. Modern research on oral infection-and, by extension, on intraoral inflammation-as a risk factor for systemic disease began with a 1989 Finnish study that reported an association between oral diseases, tooth loss, and heart disease. ${ }^{25}$ This observation was followed by studies on a variety of other potential associations, as well as research into the biological plausibility of these associations, and investigation of mechanisms that might explain potential causal relationships.

Periodontal diseases are of a joint infectious and inflammatory nature. They are characterized by the presence of supra- and subgingival biofilms, which elicit an inflammatory host response. This inflammation of periodontal tissue, diagnosed clinically by the presence of marginal bleeding and, particularly, by periodontal bleeding and increased probing depth, determines periodontal injury. Periodontal bleeding reveals the ulcerated area of subgingival tissue, whereas probing depth reveals the extent of the area of tissue covered by subgingival biofilm. Although different estimates for quantification of the area of periodontal injury have been reported in the literature, the inflammatory challenge of periodontal disease usually consists of an affected area of $15 \mathrm{~cm}^{2}$ to $72 \mathrm{~cm}^{2} .{ }^{26}$ In this setting, the inflammatory burden of untreated periodontal disease is not only present at the local level, but is also associated with the presence of biomarkers of systemic inflammation, such as C-reactive protein. ${ }^{27}$

It bears stressing that any study of the association between chronic inflammatory conditions (such as periodontal disease), cardiovascular disease, and diabetes should necessarily follow the "common risk factor approach". ${ }^{28}$ The key concept underlying this approach is that controlling a small number of risk factors may have a substantial impact on the burden of many diseases, at a lower cost and with greater efficiency and effectiveness than attempts at specific 
approaches for the control of each condition.

Many studies have investigated the biological plausibility of the association between periodontal disease and systemic disorders. Basically, there are three possible mechanisms whereby periodontal diseases may induce a remote inflammatory response:

- bacteremia;

- immune response to the presence of oral pathogens; and

- hematogenous spread of components of the infection/immune response cascade. ${ }^{19}$

The hypothesis that uses bacteremia to explain the association between periodontal disease and systemic conditions is based on the spread of bacteria from the supragingival and subgingival biofilm into the bloodstream through the ulcerated junctional epithelium of the periodontal lesion. Aside from invasive procedures such as subgingival scaling and dental extraction, which are known to produce transient bacteremia, daily activities such as brushing and chewing may also lead to dissemination of bacteria and bacterial products into the bloodstream. A double-blind clinical trial evaluated the presence of bacteremia after brushing and dental extraction and found that both were capable of inducing similar bacteremia. ${ }^{29}$ Chewing may also lead to release of endotoxins from subgingival biofilm bacteria into the bloodstream, particularly in patients with advanced periodontitis. ${ }^{30}$

The host response to oral pathogens may also explain the association between periodontal diseases and other systemic disorders. In one study, systemic levels of interleukin-6, C-reactive protein, and fibrinogen were measured before and 3 months after completion of a course of non-surgical periodontal therapy. The authors found that patients who received periodontal treatment experienced a significant reduction in levels of all three markers of systemic inflammation. ${ }^{31}$

Hematogenous spread of components of the infection/immune cascade constitutes the third potential explanation for the relationship between periodontal disease and systemic conditions. In an investigation on the presence of oral bacteria in heart valves and aortic aneurysms, Streptococcus mutans and Aggregatibacter actinomycetemcomitans were the species of oral bacteria most often isolated from heart specimens. ${ }^{32}$

\section{Association between periodontal and cardiovascular disease}

Studies on the association between periodontal and cardiovascular disease have used biological plausibility to demonstrate how periodontitis could be associated with increased risk of cardiovascular events. One important aspect that should be taken into account is the set of shared risk factors for both. ${ }^{33}$ Analysis of risk factors such as smoking, diabetes, obesity, socioeconomic status, gender, sedentary lifestyle, genetic factors, serological markers, and inflammatory mediators shows that several of these play a role in causation of periodontal and cardiovascular diseases alike.

Five systematic reviews published over the last decade support the presence of an association between periodontal and cardiovascular disease. ${ }^{34-38}$ The association itself was considered modest, but significant. A meta-analysis of cohort, case-control, and cross-sectional studies assessed the prevalence and incidence of coronary heart disease after adjustment for key factors such as age, gender, smoking, and diabetes. ${ }^{38}$ The pooled results of the cohort studies included in this analysis, comprising over 80 thousand subjects, showed that persons with periodontal disease were at a greater risk of coronary disease, as compared with controls (RR 1.14; 95\% CI 1.07-1.21; $\mathrm{p}<0.001)$. Another relevant finding from cohort studies concerns the number of remaining teeth. Interestingly, subjects with fewer than 10 teeth were also at a greater risk of coronary heart disease (RR 1.24; 95\% CI 1.14$1.36 ; \mathrm{p}<0.001)$. Analysis of case-control studies $(\mathrm{n}=1423)$ revealed an even greater risk of coronary disease (OR 2.22; 95\% CI 1.59-3.11; $\mathrm{p}<0.001$ ). Likewise, cross-sectional studies of patients with periodontal disease found a higher prevalence of coronary disease in these patients than in periodontally healthy subjects (OR 1.59; 95\% CI 1.32-1.91; $\mathrm{p}<0.001)$. In short, this meta-analysis showed that both the prevalence and incidence of coronary heart 
disease are significantly higher in persons with poor periodontal health. Periodontal disease could thus be considered a risk factor for coronary heart disease, although prospective studies (assessing the risk reduction of cardiovascular events after treatment of periodontal disease, for instance) are still required for proof of causation.

The association between markers of systemic bacterial exposure secondary to periodontal disease and cardiovascular risk was investigated in a metaanalysis of five cohort studies and seven cross-sectional studies. Assessment of these studies revealed seven investigations on coronary heart disease, four studies on myocardial infarction, and three studies evaluating carotid intima-media thickness as a marker of early-stage atherosclerosis. Bacterial exposure was detected for periodontal pathogens through serology in most studies and through bacterial load measurement or C-reactive protein levels as a surrogate marker in others. The meta-analysis found that periodontal disease with concomitant elevation of markers of bacterial exposure was strongly associated with coronary heart disease (OR 1.75; 95\% CI 1.32-2.34; p < 0.001). Increased intima-media thickness was also found in patients with periodontitis (IMT $+0.03 \mathrm{~mm}, 95 \%$ CI $0.02-0.04$ ), but no association was found between periodontal disease and myocardial infarction. Beck et al. assessed the relationship between bacterial exposure secondary to periodontal disease (as measured by levels of IgG antibodies to 17 species of oral bacteria) and cardiovascular disease in 4,846 participants. ${ }^{39}$ The authors did indeed find associations with age, gender, smoking status, hypertension, educational attainment, and $\operatorname{IgG}$ antibodies to oral organisms, but they failed to demonstrate an association between clinical signs of periodontal disease and coronary heart disease. The authors suggest that "the quality and quantity of the host response to oral bacteria may be an exposure more relevant to systemic atherothrombotic coronary events than to clinical measures". ${ }^{39}$ Another study assessing bacterial load and its relation to cardiovascular disease made note of one important factor that is consistently associated with both conditions: socioeconomic status. ${ }^{40}$ Socioeconomic conditions were associated with a wide range of variables (higher body mass index, blood pressure, lipid fractions, glycated hemoglobin, lung function, smoking status, and diabetes), but did not correlate with bacterial load. Therefore, bacterial load does not appear to explain the differences in cardiovascular risk profile associated with socioeconomic status.

A review of the Brazilian literature highlighted three studies carried out in the country that also revealed an association between periodontal and cardiovascular disease. ${ }^{19}$ A study of 361 patients with periodontitis and advanced coronary artery blockage found an odds ratio of 2.6 for the association. ${ }^{41}$ Another cross-sectional study of a sample of 634 patients found poorer periodontal health in subjects with ischemic coronary atherosclerosis. ${ }^{42}$ The third study, using a case-control design, found a significant association (OR 5.1) between periodontitis and acute coronary syndrome. ${ }^{43}$

Attempts have recently been made to elucidate the pathway to increased cardiovascular risk in periodontitis (whether predominantly due to infection or to inflammation). A randomized clinical trial compared non-surgical periodontal therapy performed with or without adjuvant antibiotics in association with clinical variables, gingival fluid, blood tests, metalloproteinases, C-reactive protein, and lipid fractions in subjects with both chronic periodontitis and coronary artery disease. Both groups experienced reductions in HDL cholesterol and apolipoprotein A, but neither group achieved a significant reduction in surrogate markers of myocardial infarction risk. ${ }^{44}$ Other interventional studies have been conducted to investigate the association, ${ }^{45,46}$ using proxy variables (endothelial function, for example) as cardiovascular outcomes. Periodontal treatment seems to improve some proinflammatory mediators and alters endothelial function, but authors suggest that definitive trials are still needed.

\section{Association between periodontal disease and adverse outcomes in pregnancy}

Birth weight is an essential determinant of the odds of neonatal survival and healthy growth and 
development. Preterm birth, defined as delivery before 37 weeks' gestation, is usually the result of preterm labor, premature rupture of membranes, or maternal or fetal complications. ${ }^{47}$ Infants are classified as "low birth weight" (LBW) when weight is lower than $2500 \mathrm{~g}$.

The estimated prevalence of preterm birth ranges from 6 to $15 \%$ across different populations. In the municipality of Porto Alegre, 2007 data from the Liveborn Infant Information System (SINASC) showed prevalence rates of $10.4 \%$ for preterm birth and $10.1 \%$ for $\mathrm{LBW}^{48}$

Infant morbidity and mortality decline as gestational age advances. Prematurity accounts for approximately half of all perinatal deaths and half of all congenital neurological deficits. Accordingly, the care of premature infants entails high costs, since they will often require prolonged admission to neonatal intensive care units and may develop respiratory, visual, cardiac, and neurologic sequelae, among other long-term complications, the severity and impact of which are directly associated with gestational age and birth weight. ${ }^{49,50}$

The presence of inflammation accounts for a substantial fraction of all preterm births. In most such cases, inflammation is secondary to intrauterine infection. However, evidence suggests that remote infections, such as appendicitis, pneumonia, and periodontitis, may trigger preterm labor. ${ }^{51-54}$

The association between periodontal disease and prematurity and/or low birth weight may be explained by three routes, just as the association between periodontal and cardiovascular disease:

- dissemination of the by-products of inflammation through the bloodstream,

- maternal/fetal immune response to the presence of oral pathogens, and

- hematogenous spread of oral bacteria..$^{50,55}$

Observational studies and clinical trials have assessed the relation between adverse gestational outcomes and periodontal diseases. Indeed, several such studies have been carried out in the Brazilian population. ${ }^{19}$ Different definitions of periodontitis, inadequate adjustment for confounders, and different methods of measuring outcomes and endpoints may partially account for the divergence of findings in the literature. Furthermore, distinct populations may not share the same risk factors for these conditions; in this context, the specific biological, socioeconomic, and environmental factors of each population should be taken into account.

Among the various study designs used for this purpose, clinical trials warrant particular attention, insofar as they are able to provide the highest level of scientific evidence. Lopez et al. (2002) conducted a clinical trial of 200 women who received periodontal therapy prior to the $28^{\text {th }}$ gestational week and 200 women who received periodontal treatment after delivery. ${ }^{56}$ The primary endpoint was delivery before 37 weeks' gestation with a birth weight of $<2500 \mathrm{~g}$. The incidence of prematurity in the experiment group was $1.8 \%$, versus $10.11 \%$ in controls. Upon multivariate analysis, the presence of periodontal disease was the main risk factor for prematurity and low birth weight. The same group of investigators carried out another study on 580 pregnant women with gingivitis who received periodontal care before 28 weeks' gestation (experimental group) and 290 pregnant women with gingivitis who received treatment after delivery (control group). The primary endpoint was the same as that of the previous study. The incidence of prematurity with low birth weight was $2.4 \%$ in the experiment group, versus $6.71 \%$ in the control group (OR 3.26; $95 \%$ CI 1.56-6.83; $\mathrm{p}=0.0009)$. Logistic regression analysis showed that pregnant women with gingivitis are at greater risk of delivering premature, LBW infants (OR 2.76; 95\% CI 1.29-5.88; p = 0.008) as compared with women who received gingivitis treatment.

These positive results were not confirmed in subsequent clinical trials. In 2006, Michalowicz et al. ${ }^{57}$ published a multi-center clinical trial performed in the United States with 823 pregnant women. Their results demonstrated that periodontal therapy did not alter the occurrence of preterm birth or low birth weight. Recently, two large clinical trials conducted in the US ${ }^{58,59}$ and Australia ${ }^{60}$ have also failed to observe a positive effect of periodontal therapy on PTLBW rates. The largest clinical trial included 1,806 participants that received scaling and root 
planing either in the second trimester of gestation or after delivery. The test group had an incidence of preterm delivery of $13.1 \%$ whereas the incidence was $11.5 \%^{58}$ in the control group. Contradictory results were also observed in recent meta-analyses. Polyzos et al. ${ }^{61}$ suggested a beneficial effect of periodontal treatment on PTLBW rates, whereas Fogacci et al. ${ }^{62}$ could not corroborate this finding.

\section{Conclusion}

Periodontal diseases should be considered systemic conditions. This means that they are both modulated by the body's systems and play a role as a risk factor for systemic derangements. The current

\section{References}

1. Page RC, Kornman KS. The pathogenesis of human periodontitis: an introduction. Periodontol 2000. 1997 Jun;14(1):9-11.

2. Bergström J. Short-term investigation on the influence of cigarette smoking upon plaque accumulation. Scand J Dent Res. 1981 Jun;89(3):235-8.

3. Cohen DW, Shapiro J, Friedman L, Kyle GC, Franklin S. A longitudinal investigation of the periodontal changes during pregnancy and fifteen months post-partum. II. J Periodontol. 1971 Oct;42(10):653-7.

4. Seymour RA, Smith DG, Rogers SR. The comparative effects of azathioprine and cyclosporin on some gingival health parameters of renal transplant patients. A longitudinal study. J Clin Periodontol. 1987 Nov;14(10):610-3.

5. Sutton RB, Smales FC. Cross-sectional study of the effects of immunosuppressive drugs on chronic periodontal disease in man. J Clin Periodontol. 1983 May;10(3):317-26.

6. Thorstensson H, Hugoson A. Periodontal disease experience in adult long-duration insulin-dependent diabetics. J Clin Periodontol. 1993 May;20(5):352-8.

7. Bergström J, Eliasson S, Dock J. A 10-year prospective study of tobacco smoking and periodontal health. J Periodontol. 2000 Aug;71(8):1338-47.

8. Machtei EE, Dunford R, Hausmann E, Grossi SG, Powell J, Cummins D, et al. Longitudinal study of prognostic factors in established periodontitis patients. J Clin Periodontol. 1997 Feb;24(2):102-9.

9. Norderyd O, Hugoson A, Grusovin G. Risk of severe periodontal disease in a Swedish adult population. a longitudinal study. J Clin Periodontol. 1999 Sep;26(9):608-15.

10. Susin C, Dalla Vecchia CF, Oppermann RV, Haugejorden O, Albandar JM. Periodontal attachment loss in an urban population of Brazilian adults: effect of demographic, be- evidence supports some of these interactions, such as smoking, as a risk factor for periodontal disease, and diabetes mellitus, as both influenced by and influencing inflammatory changes in the periodontal tissue. Other potential associations are still being researched, such as obesity, hormonal changes, cardiovascular disease, and adverse outcomes in pregnancy. These, and others, still require further investigation before the repercussions of periodontal disease can be fully elucidated. Nevertheless, at the present time, the treatment of periodontal diseases-and, most importantly, their prevention-enables adequate intervention as a means of ensuring periodontal health.

havioral, and environmental risk indicators. J Periodontol. 2004 Jul;75(7):1033-41.

11. Susin C, Oppermann RV, Haugejorden O, Albandar JM. Periodontal attachment loss attributable to cigarette smoking in an urban Brazilian population. J Clin Periodontol. 2004 Nov;31(11):951-8.

12. Papapanou PN. Periodontal diseases: epidemiology. Ann Periodontol. 1996 Nov;1(1):1-36.

13. Mealey BL, Oates TW. Diabetes mellitus and periodontal diseases. J Periodontol. 2006 Aug;77(8):1289-303.

14. Emrich LJ, Shlossman M, Genco RJ. Periodontal disease in non-insulin-dependent diabetes mellitus. J Periodontol. 1991 Feb;62(2):123-31.

15. Taylor GW, Burt BA, Becker MP, Genco RJ, Shlossman M. Glycemic control and alveolar bone loss progression in type 2 diabetes. Ann Periodontol. 1998 Jul;3(1):30-9.

16. Albandar J. Global risk factors and risk indicators for periodontal diseases. Periodontol 2000. 2002 Apr;29(1):177-206.

17. Genco RJ, Ho AW, Kopman J, Grossi SG, Dunford RG, Tedesco LA. Models to evaluate the role of stress in periodontal disease. Ann Periodontol. 1998 Jul;3(1):288-302.

18. Castro GD, Oppermann RV, Haas AN, Winter R, Alchieri JC. Association between psychosocial factors and periodontitis: a case-control study. J Clin Periodontol. 2006 Feb;33(2):109-14.

19. Weidlich P, Cimoes R, Pannuti CM, Oppermann RV. Association between periodontal diseases and systemic diseases. Braz Oral Res. 2008 Aug;22 Suppl 1:32-43.

20. Susin C, Albandar JM. Aggressive periodontitis in an urban population in southern Brazil. J Periodontol. 2005 Mar;76(3):468-75.

21. Antoniazzi RP, Miranda LA, Zanatta FB, Islabao AG, Gustafsson A, Chiapinotto GA, et al. Periodontal conditions of 
individuals with Sjogren's syndrome. J Periodontol. 2009 Mar;80(3):429-35.

22. Dalla Vecchia CF, Susin C, Rosing CK, Oppermann RV, Albandar JM. Overweight and obesity as risk indicators for periodontitis in adults. J Periodontol. 2005 Oct;76(10):1721-8.

23. Haas AN, Rosing CK, Oppermann RV, Albandar JM, Susin C. Association among menopause, hormone replacement therapy, and periodontal attachment loss in southern Brazilian women. J Periodontol. 2009 Sep;80(9):1380-7.

24. Hunter W. Oral sepsis as a cause of disease. Br Med J. 1900;2(2065):215-6.

25. Mattila K, Nieminen M, Valtonen V, Rasi V, Kesäniemi Y, Syrjälä S, et al. Association between dental health and acute myocardial infarction. BMJ. 1989 Mar;298(6676):779-81.

26. Page RC, Offenbacher S, Schroeder HE, Seymour GJ, Kornman KS. Advances in the pathogenesis of periodontitis: summary of developments, clinical implications and future directions. Periodontol 2000. 1997 Jun;14(1):216-48.

27. Beck J, Slade G, Offenbacher S. Oral disease, cardiovascular disease and systemic inflammation. Periodontol 2000. 2000 Jun;23(1):110-20.

28. Sheiham A, Watt R. The common risk factor approach: a rational basis for promoting oral health. Community Dent Oral Epidemiol. 2000 Jun;28(6):399-406.

29. Lockhart P, Brennan M, Sasser H, Fox P, Paster B, BahraniMougeot F. Bacteremia associated with toothbrushing and dental extraction. Circulation. 2008 Jun;117(24):3118-25.

30. Geerts S, Nys M, De M, Charpentier J, Albert A, Legrand V, et al. Systemic release of endotoxins induced by gentle mastication: association with periodontitis severity. J Periodontol. 2002 Jan; $73(1): 73-8$.

31. Vidal F, Figueredo C, Cordovil I, Fischer R. Periodontal therapy reduces plasma levels of interleukin-6, C-reactive protein, and fibrinogen in patients with severe periodontitis and refractory arterial hypertension. J Periodontol. 2009 May;80(5):786-91.

32. Nakano K, Nemoto H, Nomura R, Inaba H, Yoshioka H, Taniguchi K, et al. Detection of oral bacteria in cardiovascular specimens. Oral Microbiol Immunol. 2009 Feb;24(1):64-8

33. Joshipura K. The relationship between oral conditions and ischemic stroke and peripheral vascular disease. J Am Dent Assoc. 2002 Jun;133 Suppl:23S-30S.

34. Scannapieco FA, Bush RB, Paju S. Associations between periodontal disease and risk for atherosclerosis, cardiovascular disease, and stroke. A systematic review. Ann Periodontol. 2003 Dec;8(1):38-53.

35. Khader YS, Albashaireh ZS, Alomari MA. Periodontal diseases and the risk of coronary heart and cerebrovascular diseases: a meta-analysis. J Periodontol. 2004 Aug;75(8):1046-53.

36. Vettore MV. Periodontal disease and cardiovascular disease. Evid Based Dent. 2004;5(3):69.
37. Meurman JH, Sanz M, Janket SJ. Oral health, atherosclerosis, and cardiovascular disease. Crit Rev Oral Biol Med. 2004 Nov;15(6):403-13.

38. Bahekar AA, Singh S, Saha S, Molnar J, Arora R. The prevalence and incidence of coronary heart disease is significantly increased in periodontitis: a meta-analysis. Am Heart J. 2007 Nov;154(5):830-7.

39. Beck J, Eke P, Heiss G, Madianos P, Couper D, Lin D, et al. Periodontal disease and coronary heart disease: a reappraisal of the exposure. Circulation. 2005 Jul;112(1):19-24.

40. Steptoe A, Shamaei-Tousi A, Gylfe A, Henderson B, Bergstrom S, Marmot M. Socioeconomic status, pathogen burden and cardiovascular disease risk. Heart. 2007 Dec;93(12):1567-70.

41. Accarini R, de Godoy MF. Periodontal disease as a potential risk factor for acute coronary syndromes. Arq Bras Cardiol. 2006 Nov;87(5):592-6.

42. Barilli AL, Passos AD, Marin-Neto JA, Franco LJ. Periodontal disease in patients with ischemic coronary atherosclerosis at a University Hospital. Arq Bras Cardiol. 2006 Dec;87(6):695-700.

43. Rech RL, Nurkin N, da Cruz I, Sostizzo F, Baiao C, Perrone $\mathrm{JA}$, et al. Association between periodontal disease and acute coronary syndrome. Arq Bras Cardiol. 2007 Feb;88(2):185-90.

44. Tuter G, Kurtis B, Serdar M, Aykan T, Okyay K, Yucel A, et al. Effects of scaling and root planing and sub-antimicrobial dose doxycycline on oral and systemic biomarkers of disease in patients with both chronic periodontitis and coronary artery disease. J Clin Periodontol. 2007 Aug;34(8):673-81.

45. D'Aiuto F, Ready D, Tonetti MS. Periodontal disease and Creactive protein-associated cardiovascular risk. J Periodontal Res. 2004 Aug;39(4):236-41.

46. Tonetti MS, D’Aiuto F, Nibali L, Donald A, Storry C, Parkar $\mathrm{M}$, et al. Treatment of periodontitis and endothelial function. N Engl J Med. 2007 Mar;356(9):911-20.

47. Williams CE, Davenport ES, Sterne JA, Sivapathasundaram V, Fearne JM, Curtis MA. Mechanisms of risk in preterm lowbirthweight infants. Periodontol 2000. 2000 Jun;23(1):142-50.

48. Prefeitura Municipal de Porto Alegre. Secretaria Municipal da Saúde. Equipe de Vigilância de Eventos Vitais, Doenças e Agravos não Transmissíveis. Informações referentes ao número de nascidos vivos em Porto Alegre, variáveis maternas, do parto e do recém nascido. Porto Alegre: Prefeitura Municipal de Porto Alegre; 2007. 26 p.

49. Michalowicz BS, Durand R. Maternal periodontal disease and spontaneous preterm birth. Periodontol 2000. 2007 Jun;44(1):103-12.

50. Goldenberg RL, Hauth JC, Andrews WW. Intrauterine infection and preterm delivery. N Engl J Med. 2000 May;342(20):1500-7.

51. Goffinet F. Primary predictors of preterm labour. BJOG. 2005 Mar;112 Suppl 1:38-47.

52. Goldenberg RL. The management of preterm labor. Obstet Gynecol. 2002 Nov;100(5 Pt 1):1020-37. 
53. Slattery MM, Morrison JJ. Preterm delivery. Lancet. 2002 Nov;360(9344):1489-97.

54. Klebanoff M, Searle K. The role of inflammation in preterm birth--focus on periodontitis. BJOG. 2006 Dec;113 Suppl 3:43-5.

55. Pretorius C, Jagatt A, Lamont RF. The relationship between periodontal disease, bacterial vaginosis, and preterm birth. J Perinat Med. 2007 Apr;35(2):93-9.

56. Lopez NJ, Smith PC, Gutierrez J. Higher risk of preterm birth and low birth weight in women with periodontal disease. J Dent Res. 2002 Jan;81(1):58-63.

57. Michalowicz BS, Hodges JS, DiAngelis AJ, Lupo VR, Novak MJ, Ferguson JE, et al. Treatment of periodontal disease and the risk of preterm birth. N Engl J Med. 2006 Nov;355(18):1885-94.

58. Offenbacher S, Beck JD, Jared HL, Mauriello SM, Mendoza LC, Couper DJ, et al. Effects of periodontal therapy on rate of preterm delivery: a randomized controlled trial. Obstet Gynecol. 2009 Sep;114(3):551-9.
59. Macones GA, Parry S, Nelson DB, Strauss JF, Ludmir J, Cohen AW, et al. Treatment of localized periodontal disease in pregnancy does not reduce the occurrence of preterm birth: results from the Periodontal Infections and Prematurity Study (PIPS). Am J Obstet Gynecol. 2010 Feb;202(2):147.e1-8.

60. Newnham JP, Newnham IA, Ball CM, Wright M, Pennell CE, Swain J, et al. Treatment of periodontal disease during pregnancy: a randomized controlled trial. Obstet Gynecol. 2009 Dec;114(6):1239-48.

61. Polyzos NP, Polyzos IP, Mauri D, Tzioras S, Tsappi M, Cortinovis I, et al. Effect of periodontal disease treatment during pregnancy on preterm birth incidence: a metaanalysis of randomized trials. Am J Obstet Gynecol. 2009 Mar;200(3):225-32.

62. Fogacci MF, Vettore MV, Leão AT. The effect of periodontal therapy on preterm low birth weight: a meta-analysis. Obstet Gynecol. 2011 Jan;117(1):153-65. 